\title{
CHARACTERIZATION OF THE NON-AERATED FLOW REGION IN A STEPPED SPILLWAY BY
}

\section{PIV}

António Amador,

Hydraulic and Environmental Dept. of Technologic School of Barreiro, IPS, R. Stinville n 14 Quimiparque Barreiro 2830-144, Portugal, Ph:(+351)212064660, Fax:(+351)212075002, e-mail:

antonio.amador@estbarreiro.ips.pt

Martí Sánchez-Juny and Josep Dolz.

Hydraulic, Maritime and Environmental Dept. of Polythecnic University of Catalonia (UPC), C. Jordi Girona Campus Nord 1/3 Ed. D1, Barcelona 08034, Spain, Ph: (+34)934016481, e-mail: marti.sanchez@upc.edu, j.dolz@upc.edu.

ABSTRACT: The development of the roller compacted concrete as a technique of constructing dams and the stepped surface that results from the construction procedure opened a renewal interest in stepped spillways. Previous research has focused in studying the air-water flow down the stepped chute with objective of obtaining better design guidelines. The non aerated flow region enlarges as the flow rate increases and there is a lack of knowledge on the hydraulic performance of stepped spillways at high velocities that undermines its use in fear of cavitation damage. In the present study the developing flow region in a stepped channel with a slope $1 \mathrm{v}: 0.8 \mathrm{~h}$ is characterized using a particle image velocimetry technique. An expression for the growth of the boundary layer thickness is proposed based on the streamwise distance from the channel crest and the roughness height. The local flow resistance coefficient is calculated by application of the Von Karman's integral momentum equation. The shear strain, vorticity and swirling strength maps obtained from the mean velocity gradient tensor are presented. Also the fluctuating velocity field is assessed. The turbulent kinetic energy map indicates the region near the pseudo-bottom (imaginary line joining two adjacent step edges) as the most active in terms of Reynolds stresses. The turbulence was found to be very intense with maximum levels of turbulence intensity from 0.40 to 0.65 measured near the pseudo-bottom. Finally the quadrant analysis of the velocity fluctuations suggests the presence of strong outflows of fluid from the cavities as well as inflows into the cavities. It is conjectured that the mass transfer/exchange between cavities and main stream, play an important role in the high levels of turbulent energy observed.

KEYWORDS: Stepped spillway; Skimming flow; Flow characteristics; Boundary layer; Turbulence. 


\section{INTRODUCTION}

The development of new construction techniques (e.g. roller compacted concrete) are directly responsible for a renewal in interest for stepped spillways and a number of research projects have been conducted over the past three decades [1-3].

For a given stepped geometry the flow regime can be either: nappe; transition or skimming flow. Nappe flow occurs at low flows and can be characterized by a succession of free falling nappes [3]. In skimmimg flow, the water flows as a coherent stream over the pseudobottom formed by the outer step edges, beneath it threedimensional cavity vortices develop and recirculation is maintained through transmission of shear from the main stream [4]. Between the upper limit of nappe flow and the onset of skimming flow a transition flow exists separating these characteristic limits [5].

Skimming flow is usually found for typical design discharges of stepped spillways. The flow along the chute can be divided into distinct regions. In the initial flow stage there is no air entrainment, the free surface is smooth and glassy, next to the stepped invert turbulence is generated and the boundary layer develops. The start of natural air entrainment is defined by the point where the boundary layer reaches the water surface and the turbulent energy of the vortices is large enough to exceed the surface tension and gravity effects. Downstream rapid and strong free-surface aeration is observed.

Previous research has focused on studying the air-water flow down a stepped chute with objective of obtaining better design guidelines [5-7]. Most studies did not investigate the turbulence characteristics with exception of $[8,9]$.

The non aerated flow region enlarges as the flow rate increases and there is a lack of knowledge on the hydraulic performance of stepped spillways at high velocities that undermines its use in fear of cavitation damage [10]. In the present work an experimental study was conducted to study the non aerated flow region on a large model flume using particle image velocimetry (PIV) instrumentation. The use of this non-intrusive technique aimed at improving the understanding of the physical processes responsible for enhancement of turbulence production. The effects of the steps on the mean and fluctuating velocity field are investigated and discussed. The behaviour of the separated free shear layer formed behind the roughness elements is studied and the wall shear stress is determined. An effort is made to identify coherent structures that may contribute to turbulence production.

\section{EXPERIMENTAL SETUP}

The experiments were conducted in a rectangular stepped channel assembled at $A$ Coruna University and is 0.50 $\mathrm{m}$ wide, $2.0 \mathrm{~m}$ high (from crest to toe) and step height (h) of $0.05 \mathrm{~m}$. The bottom inclination is $51.3^{\circ}$ 
corresponding to a slope of 1:0.8 (v:h) typical of RCC dams (Fig. 1). The tested unit water discharge (q) was $0.11 \mathrm{~m}^{2} / \mathrm{s}$ that corresponds to a Reynolds number $(\mathrm{Re}=\mathrm{q} / \mathrm{v})$ of $1.1 \times 10^{5}$. The electromagnetic flowmeter installed in the supply conduit of the model had an accuracy of $\pm 2 \%$.

The PIV system is composed of a double-pulsed Nd-Yag laser, with $400 \mathrm{~mJ}$ of energy per pulse, a $1024 \times 1280$

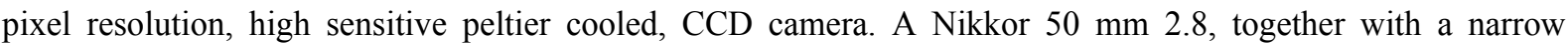
bandwidth filter that passes the $532 \mathrm{~nm}$ light from the Nd-Yag laser, is mounted on the CCD camera. An electronic sequencer synchronizes the camera and laser pulses.

The water was seeded with $70 \mu \mathrm{m}$ ceramic micro spheres. The images cover two steps. Bigger measurement areas imply unacceptable perspective errors (Fig. 1). The camera captured double frame, double exposure particle images. The separation time was adjusted at 200-250 $\mu$ s between two laser pulses in order to give a maximum particle image displacement of eight pixels.

a)

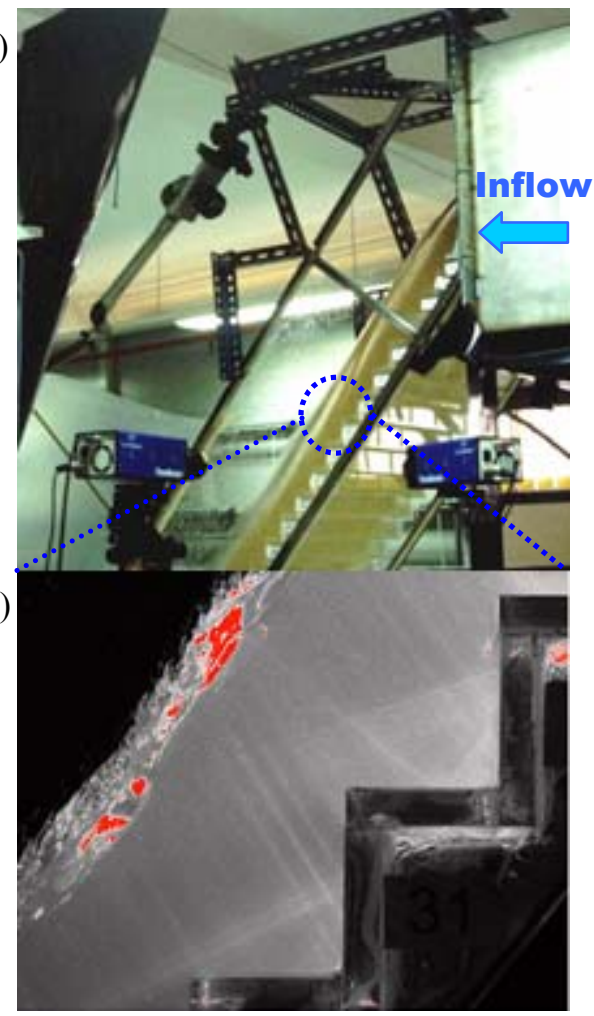

Fig. 1 - a) Developing flow region in stepped spillway with $q=0.11 \mathrm{~m}^{2} / \mathrm{s}, \mathrm{h}=0.05 \mathrm{~m}, \alpha=51.3^{\circ}$. b) Image captured by CCD camera for steps E34 $(\mathrm{X} / \mathrm{ks}=13.04)$ and $\mathrm{E} 33$ at $(\mathrm{X} / \mathrm{ks}=15.09)$.

Both image frames are subdivided into small interrogation areas that are partially overlapping. Interrogation areas at identical positions in the images frames are correlated by means of Fast Fourier Transformation. From 
the two dimensional cross-correlation function, the position of the highest peak representing the mean displacement of the particle images is estimated. In order to obtain high-accuracy estimators of the particle displacements, the correlation peak position is calculated at sub-pixel level by the three point Gaussian interpolation scheme. The accuracy of the resulting PIV estimators is about 0.1 pixel, which in the present study corresponds to an accuracy regarding the measured velocities of $50-62.5 \mathrm{~mm} / \mathrm{s}$.

Zero offsetting is applied in order to optimize the signal and to minimize biasing effects in the PIV estimators [11]. The interrogation of the images initiates with large dimensions of the interrogation areas that are reduced in size after each interrogation. In this way, high dynamic velocity ranges can be combined with a high spatial resolution. In this study adaptive interrogation area sizes have been used from $128 \times 128$ pixels to $32 \times 32$ pixels, with an overlapping of 50\% (i.e. 16 pixels ).

Some data sets are checked on peak-locking effects by examining the statistics of the PIV estimators at subpixel level. All data are validated on outliers by the median test $[12,13]$. Detected outliers are substituted by the local mean value of its neighbouring estimators.

A total number of 500 velocity fields have been recorded with separation time of one second. Statistical independency of each velocity field has been investigated by calculating the temporal correlation of the velocities at a specific location in the flow. Therefore a location in the upper region of the overlying flow, the shear layer and within the step cavity has been observed. For all three locations no velocity correlation is found already after a time delay of one second. The statistical sampling theory is used to assess the errors in the computed mean and RMS as a function of a given number of samples. The error interval for the mean velocity $\left(\varepsilon_{\text {mean }}\right)$ is defined as follows [14] :

$$
\varepsilon_{\text {mean }}= \pm \frac{Z \cdot \sigma}{\sqrt{N}}
$$

where $\mathrm{Z}$ is a factor related with the confidence level, $\sigma$ is the standard deviation of the velocity for an infinite number of samples, and $\mathrm{N}$ is the number of samples.

Similarly, the relative error interval for the RMS velocity $\left(\varepsilon_{\mathrm{RMS}}\right)$ can be computed from [14]:

$$
\varepsilon_{R M S}= \pm \frac{Z}{\sqrt{2 N}}
$$

In the above expressions, $Z=1.96$ is used, which corresponds to a confidence level of $95 \%$. Therefore for the RMS velocity the computed interval is $\varepsilon_{\mathrm{RMS}}= \pm 62.0 \mathrm{~mm} / \mathrm{s}$ (roughly $6 \%$ of the standard deviation velocity). The error interval for the mean velocity depends on the local turbulence level. The estimated error intervals for the 
mean velocity are $\varepsilon_{\text {mean }}= \pm 10.0 \mathrm{~mm} / \mathrm{s}(0.3 \%$ of the computed mean velocity $)$ in the upper region of the overlying flow, $\varepsilon_{\text {mean }}= \pm 43.6 \mathrm{~mm} / \mathrm{s}(2.7 \%$ of the computed mean velocity $)$ in the shear layer and finally $\varepsilon_{\text {mean }}= \pm 30.1 \mathrm{~mm} / \mathrm{s}$ ( $5.9 \%$ of the computed mean velocity) within the step cavity.

The study region comprises seven steps. The distance from the spillway crest to their outer edges (X) is respectively of $0.343 \mathrm{~m}$ (step E35), $0.407 \mathrm{~m}$ (step E34), $0.471 \mathrm{~m}$ (step E33), $0.535 \mathrm{~m}$ (step E32), $0.599 \mathrm{~m}$ (step E31), $0.663 \mathrm{~m}$ (step E30) and $0.727 \mathrm{~m}$ (step E29).

\section{MEAN VELOCITY FIELD}

The mean velocity field over the seven steps were obtained from 500 instantaneous velocity fields. The velocity vector spacing is $2.0 \mathrm{~mm}$ (i.e. 16 pixels) and kriging interpolation was chosen as gridding method.

From the mean velocity contour map, shown in Fig. 2, it can be observed that the flow is accelerating and developing in the downstream direction. The flow over the steps consists of a turbulent boundary layer next to the pseudo-bottom (imaginary line joining two adjacent step edges) and a frictionless fluid flow region above. Near the free surface the velocity varies from 2.8 to $3.7 \mathrm{~m} / \mathrm{s}$, corresponding to the potential flow velocity.

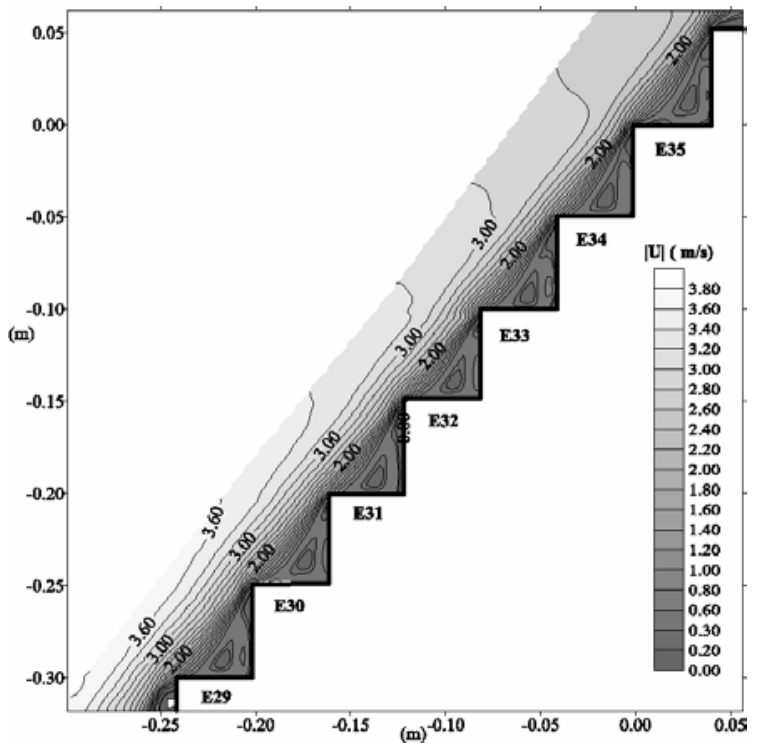

Fig. 2 - Contour map of mean absolute velocity $(|\mathrm{U}|)$.

A well defined recirculation zone occupies part of the step cavities. The quasi-steady rollers are maintained through the transmission of shear stress from the overlying flow [15]. Considering the recirculatory motion a solid body rotation, for an equivalent circumference trajectory of $2 \mathrm{~cm}$, the angular velocity and frequency of rotation were estimated to be approximately $40-50 \mathrm{rads}^{-1}$ and $6-8 \mathrm{~Hz}$ in the steps studied. 


\section{Turbulent boundary layer}

The boundary layer growth in the study region was evaluated. The boundary layer thickness $(\delta)$ is defined as the perpendicular distance from the pseudo-bottom to where the velocity is $99 \%$ of its maximum value $\left(\mathrm{U}_{0}\right)$. The boundary thickness was obtained from the forty velocity profiles obtained over steps E34, E33, E31 and E29 (Fig. 3). This is a difficult quantity to estimate, since it depends on measurements of small velocity differences and of the irregular behaviour of the outer edge of the boundary layer. The development of the boundary layer may be expressed by [16] :

$$
\frac{\delta}{X}=a \cdot\left(\frac{X}{k_{S}}\right)^{-b}
$$

where $\mathrm{X}$ is the streamwise distance from the start of the growth of the boundary layer assumed to be the spillway crest; $\mathrm{k}_{\mathrm{s}}$ is the roughness height $\mathrm{k}_{\mathrm{s}}=\mathrm{h} \cdot \cos \alpha$, and " $\mathrm{a}$ " and " $\mathrm{b}$ " are constants which according with the experimental results are equal to: $\mathrm{a}=0.112$ and $\mathrm{b}=0.309$.

In Fig. 3 is also shown other integral measures of the boundary layer obtained from the velocity profiles, as the displacement thickness $\left(\delta^{*}\right)$ :

$$
\delta^{*}=\int_{0}^{\delta}\left(1-\frac{U(y)}{U_{0}}\right) \cdot d y
$$

the momentum thickness $(\theta)$ :

$$
\theta=\int_{0}^{\delta} \frac{U(y)}{U_{0}}\left(1-\frac{U(y)}{U_{0}}\right) \cdot d y
$$

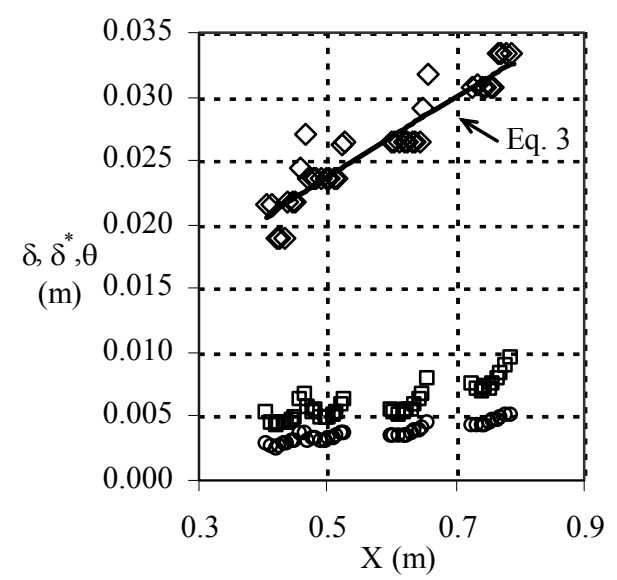

Fig. 3 - Evolution of the $\delta(\diamond), \delta^{*}(\square), \theta(\circ)$. 
The use of the von Karman integral momentum equation [17] allows the estimation of the flow resistance coefficient $\left(\mathrm{c}_{\mathrm{f}}\right)$ in the developing flow region:

$$
c_{f} \equiv \frac{\tau_{w}}{\frac{1}{2} \rho U_{0}^{2}}=2 \frac{d \theta}{d x}+\frac{\left(4 \theta+2 \delta^{*}\right)}{U_{0}} \frac{d U_{0}}{d x}
$$

where $\tau_{\mathrm{w}}=$ pseudo-bottom shear stress.

It was considered that the momentum thickness $(\theta)$ increased linearly in the flow direction $(\mathrm{x})$ in accordance with [18] that studied a similar surface. The data analysis gave a $\mathrm{d} \theta / \mathrm{dx}=0.0052$. The term $\mathrm{dU} \mathrm{U}_{0} / \mathrm{dx}$ is deduced from the Bernoulli equation. In Fig. 4 is plotted the flow resistance calculations for four step cavities. The $c_{f}$ seem to present a linear growth at each half end of the step cavity and a global constant mean value of 0.031 for all step cavities.

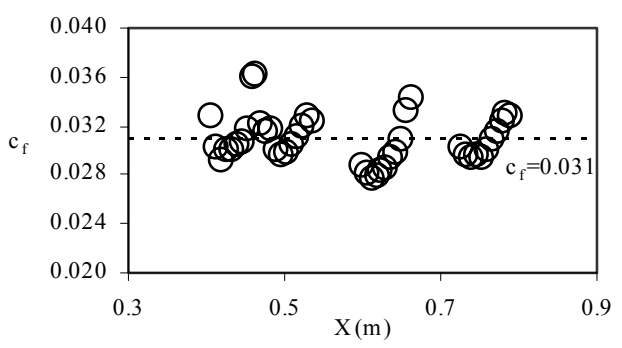

Fig. 4 - Flow resistance coefficient $\left(\mathrm{c}_{\mathrm{f}}\right)$ along the stepped spillway.

\section{Velocity distribution}

The mean velocity distribution can be divided in two zones: above the boundary layer, where the mean velocity can be considered constant and equal to the ideal-fluid flow velocity $\left(\mathrm{U}_{0}\right)$ and the boundary layer where the mean velocity gradient is relevant. In Fig. 5 mean velocity profiles normal to the pseudo-bottom and taken at different positions along the step cavities of the steps E34, E33, E31 and E29 are shown. It can be appreciated that the velocity profiles in the boundary layer are self-similar using as characteristic scales $\mathrm{U}_{0}(\mathrm{X})$ and $\delta(\mathrm{X})$. At the step edges, the velocity distribution in the boundary layer can be approximated by a power law [3]:

$$
\frac{U}{U_{0}}=\left(\frac{y}{\delta}\right)^{1 / N}
$$

The exponent $\mathrm{N}$ determined for the four step edges is around 3.0 in close agreement with the value of 3.3 obtained by [6] using a flushed Pitot tube in a similar model of a stepped spillway. In conventional smooth spillways the value of $\mathrm{N}=6.0$ from the analysis of $[19,20]$, is usually suggested for the developing boundary 
layer upstream of the inception point. The comparison shows that the mean velocity profile rises much more steeply from the reference level $(\mathrm{y}=0)$ in smooth spillways than in stepped spillways and then is flatter away from the "bottom".

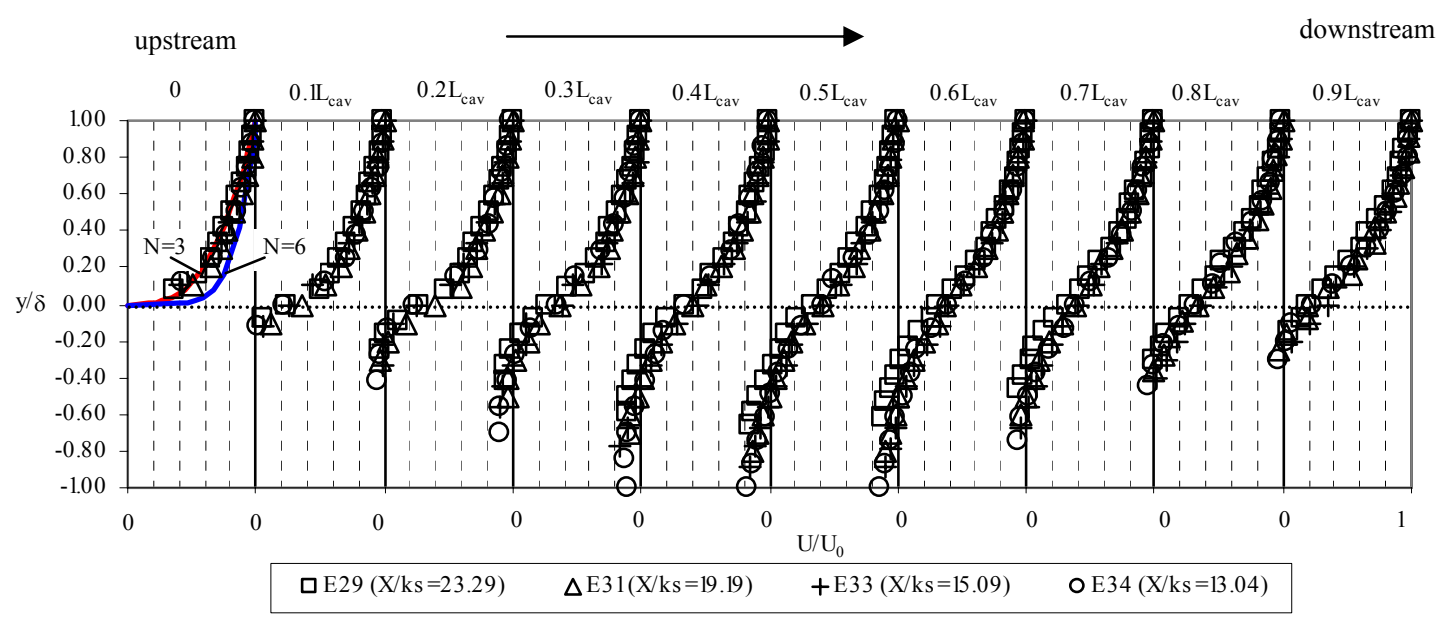

Fig. 5 - Mean velocity profiles $\left(\mathrm{U} / \mathrm{U}_{0}\right)$ normal to the pseudo-bottom, along the step cavities $\left(\mathrm{L}_{\text {cav }}\right)$ analyzed.

Between the step edges $\left(0<\mathrm{x}<\mathrm{L}_{\text {cav }}\right)$, the velocity profiles suggest a local developing mixing layer that forms at the step edge. Defining the characteristic width (b) of the mixing layer as [17]:

$$
b(x)=y_{0.9}(x)-y_{0.1}(x)
$$

where $\mathrm{y}_{\alpha}$ is the coordinate $\mathrm{y}$ where $\mathrm{U}=\alpha \mathrm{U}_{0}$.

In Fig. 6 it is shown the spreading of the mixing layer by plotting the evolution of $\mathrm{y}_{0.9} / \mathrm{k}_{\mathrm{s}}$ and $\mathrm{y}_{0.1} / \mathrm{k}_{\mathrm{s}}$ along the cavities of steps E34, E33, E31 and E29. It seems that the mixing layer spreads linearly with a maximum of $b$ at $\mathrm{x} / \mathrm{L}_{\mathrm{cav}}=0.7$. The displacement of $\mathrm{y}_{0.1}$ to the interior of the cavitiy is much more noticeable than the variation of $\mathrm{y}_{0.9}$ to the free surface. This is a typical characteristic of a mixing layer that spreads preferentially into the low speed stream [17]. The maximum reverse flow velocities found in the recirculation zone are $0.15 \mathrm{U}_{0}$ and are located near the step surfaces.

\section{Mean velocity gradient tensor}

The 2D PIV data provides two velocity components. This data can be differentiated in two directions and thus some terms of the mean velocity gradient tensor or deformation tensor can be estimated with PIV. Therefore the spanwise vorticity $\left(\omega_{\mathrm{z}}\right)$ and in-plane shear strain $\left(\varepsilon_{\mathrm{xy}}\right)$ can be determined as follows:

$$
\omega_{z}=\frac{d V}{d x}-\frac{d U}{d y}
$$




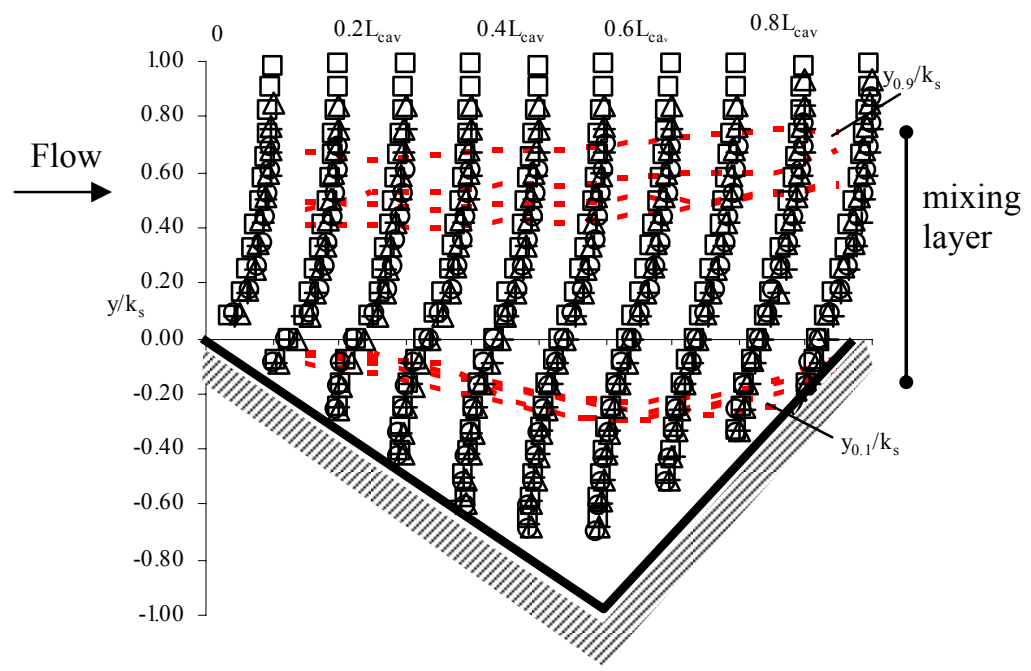

Fig. 6 - Mean velocity profiles $\left(\mathrm{U} / \mathrm{U}_{0}\right)$ and variation of $\mathrm{y}_{\alpha}$ along the step cavities analyzed. Symbols as in Fig. 5.

$$
\varepsilon_{x y}=\frac{d U}{d y}+\frac{d V}{d x}
$$

The second order central-difference scheme was employed for estimation of the spatial derivatives, this scheme is implemented for data spaced at uniform $\Delta \mathrm{X}$, according:

$$
\left(\frac{d \phi}{d x}\right)_{i}=\frac{\phi_{i+1}-\phi_{i-1}}{2 \Delta X} \quad O\left(\Delta X^{2}\right)
$$

The shear strain contour map (Fig. 7) shows maximum levels just behind the step edge, where the separation of the shear layer begins. The peaks of shear strain develop in the flow direction, highlighting the pseudo-bottom as the most active zone in terms of shear stress. A gradual decrease of the shear strain is observed towards the free surface, where the flow can be considered irrotational.

Assuming the turbulent-viscosity hypothesis valid, as the production/generation of turbulent kinetic energy $(\mathrm{P})$ is defined by [17]:

$$
P=-\overline{u^{\prime} \cdot v^{\prime}} \cdot \varepsilon_{x y}=v_{t} \cdot \varepsilon_{x y} \cdot \varepsilon_{x y}
$$

where $\overline{u^{\prime} \cdot v^{\prime}}$ is the mean Reynolds shear stress and $v_{\mathrm{t}}$ is the turbulent viscosity.

The production (P) is proportional to the mean shear strain rate. It is possible then to identify the zone just behind the outer step edge as a region of formation and growth of large-scale turbulent structures, associated with local pressure reduction in the vicinity of the vortex cores. 


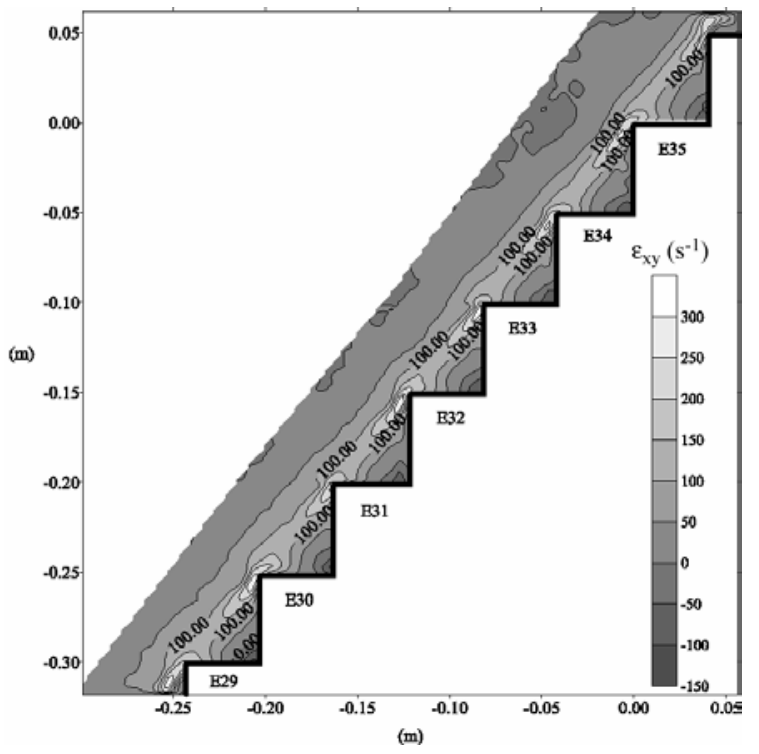

Fig. 7 - Contour map of mean shear strain $\left(\varepsilon_{x y}\right)$.

The vorticity contour map (Fig. 8) presents a similar pattern with the shear strain map; the negative vorticity is due to counter clockwise rotation. Very high levels of vorticity are generated immediately downstream of the corner and occur over a relatively small characteristic thickness. This is most likely linked to the rapid onset of small-scale vortical structures, which appear immediately downstream the leading corner of the cavity. The dominant vorticity levels extend along the separated shear layer between the leading (upstream) and trailing (downstream) corners of the steps. Within the cavity, the flow pattern exhibit a large-scale recirculation flow, the vorticity results from agglomeration of the small scale concentrations. The vorticity level inside the cavity varies between 80 and $100 \mathrm{~s}^{-1}$, which is in close agreement with the angular velocities estimated from the mean velocity field for the large recirculation zone, following the Stokes theorem equation.

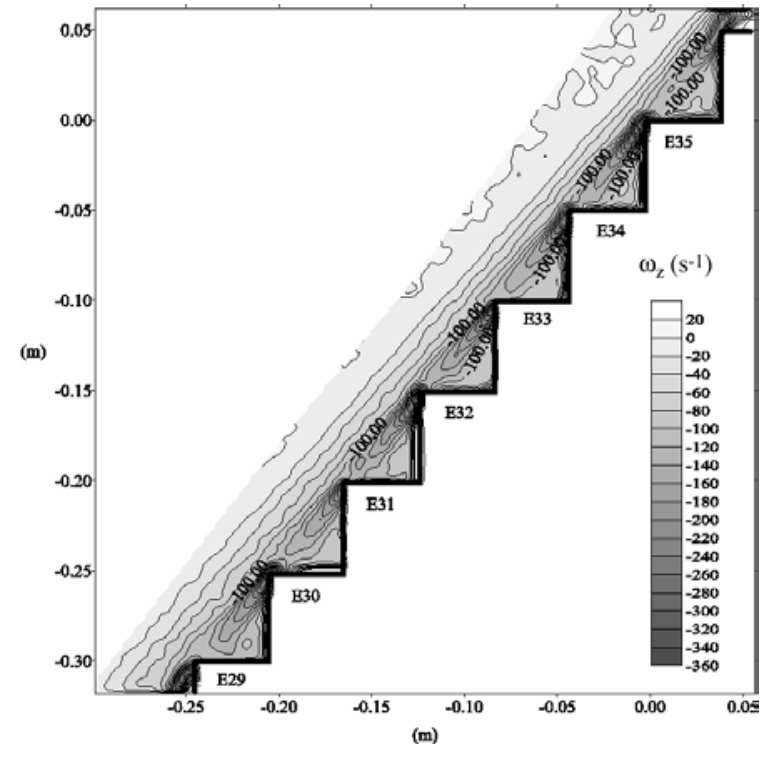

Fig. 8 - Contour map of mean spanwise vorticity $\left(\omega_{z}\right)$. 
The vorticity not only identifies vortex cores but also any shearing motion present in the flow. [21] proposed vortex identification based on the swirling strength. This method does not reveal regions which contain significant vorticity but do not have any local swirling motion (i.e. shear layers). It is based on the analysis of the mean, local velocity gradient tensor and its corresponding eigenvalues. The local 2D velocity gradient tensor will either have two real eigenvalues $\left(\lambda_{\mathrm{r}}\right)$ or a pair of complex conjugate eigenvalues $\left(\lambda_{\mathrm{cr}} \pm \lambda_{\mathrm{ci}}\right)$. The vortices are identified by plotting iso-regions of $\lambda_{\mathrm{ci}}>0$ [21]. Iso-regions of swirling strength are shown in Fig. 9. Swirling strength is noted just behind the step edge and inside the cavity due to the presence of the recirculation vortex. This quantity proved to be more useful than vorticity as a means of identifying eddies.

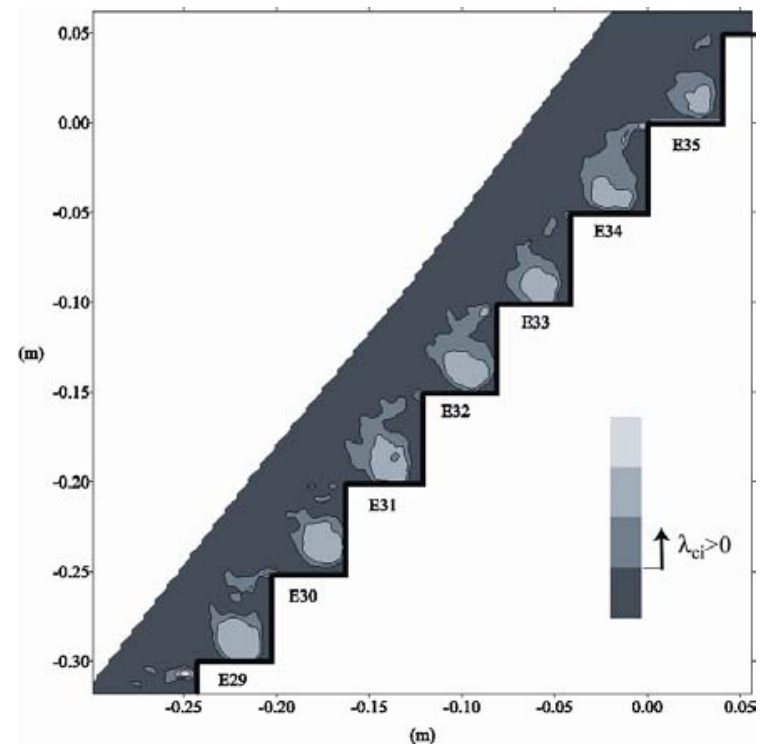

Fig. 9 - Contour map of swirling strength.

\section{TURBULENCE CHARACTERISTICS}

The 500 velocity fields measured allow studying the mean velocity field and the fluctuating velocity field.

The turbulent kinetic energy was chosen to represent the turbulent flow field. As the spanwise velocity component is not available, it is estimated from the other two components. The turbulent kinetic energy (k) is then expressed by [22]:

$k=\frac{3}{4} \cdot\left(\overline{u^{\prime 2}}+\overline{v^{\prime 2}}\right)$

where $u^{\prime}=u-U$ is the velocity fluctuation in the streamwise direction, $v^{\prime}=v-V$ the velocity fluctuation in the transverse direction.

Figure 10 confirms that the maximum turbulent kinetic energy is located in the region near the pseudo-bottom. In the shear strain field (Fig. 7) the region of production of turbulent kinetic energy was identified: the mean 
velocity gradient removes kinetic energy from the mean flow and transfers it to the fluctuating velocity field. Also it can be observed the turbulent kinetic energy levels increasing in the downstream direction with more and more important values appearing in the overlying flow closer to the free surface.

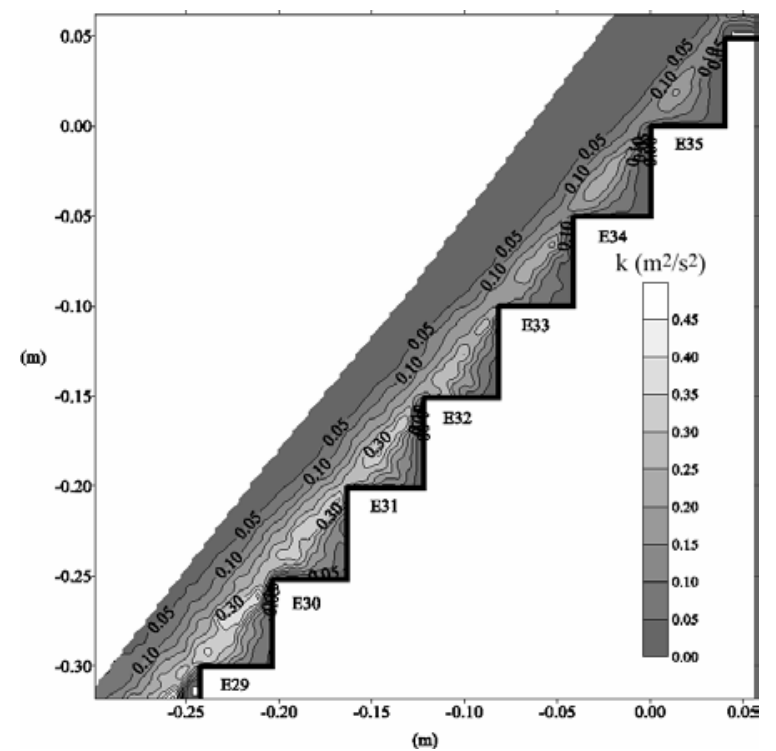

Fig. 10 - Contour map of turbulent kinetic energy (k).

\section{Turbulence intensity distribution}

As for the mean velocity, ten equally spaced turbulence intensity profiles were obtained over the cavities of steps E34, E33, E31 and E29.

The turbulence intensity in the flow direction $\left(\mathrm{T}_{\mathrm{u}}\right)$ is defined as:

$$
T_{u}(y)=\frac{\sigma_{u}(y)}{U(y)}
$$

where $\sigma_{u}(y)$ is the root mean square of the streamwise component of turbulent velocity and $U(y)$ is the mean streamwise velocity at y coordinate.

A gradual reduction of the turbulence intensity towards the edge of the boundary layer $(\delta)$ can be observed in Fig. 11. In the transition between the boundary layer and the irrotational flow region were measured turbulence intensity $\left(\mathrm{T}_{\mathrm{u}}\right)$ levels of 0.04 . Near the pseudo-bottom $(\mathrm{y} / \delta \approx 0)$ the turbulence intensity ranges from 0.40 to 0.65 . The degree of turbulence intensity is much higher than the maximum levels reported for a turbulent boundary layer over a smooth open channel, $T_{u}=0.2[23]$. The increase in the magnitudes of the flow turbulence will cause larger pressure fluctuations over the boundary surfaces of the steps than the usually found over a conventional smooth spillway. 


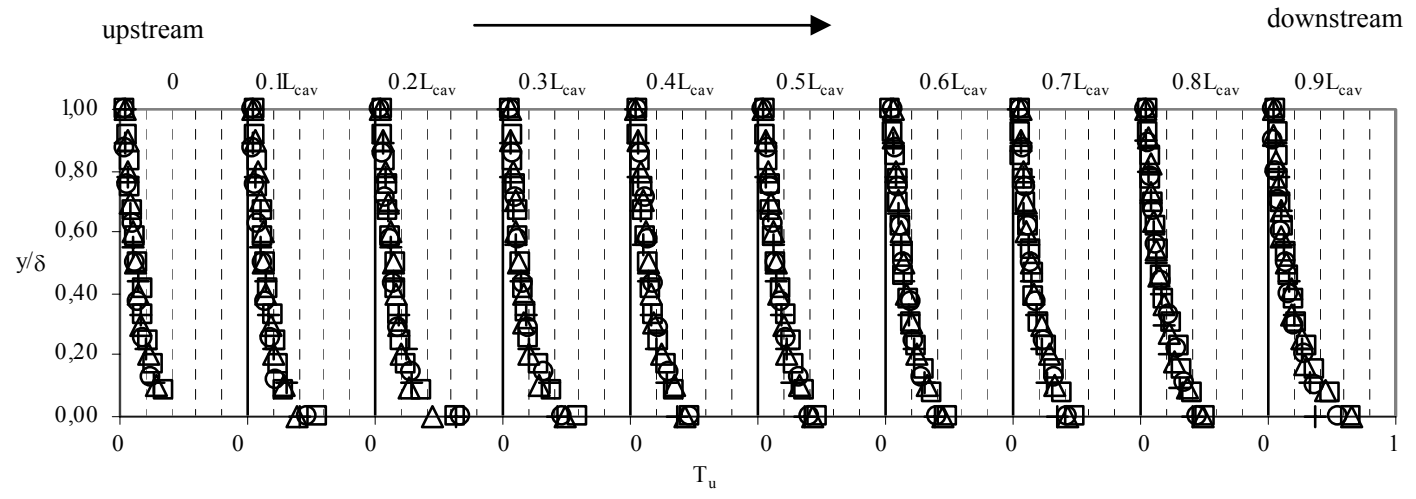

Fig. 11 - Turbulence intensity $\left(\mathrm{T}_{\mathrm{u}}\right)$ profiles normal to the pseudo-bottom, along the step cavities analysed. Symbols as in Fig. 5.

\section{Quadrant Analysis}

The u'v' quadrant splitting scheme is one of the existent eduction techniques to study turbulent structures [24]. This technique is based on the joint distribution of the velocity fluctuations on both longitudinal $\left(u^{\prime}=u-U\right)$ and vertical $\left(v^{\prime}=v-V\right)$ components. Four quadrants are defined in the $u^{\prime} v^{\prime}$ plane (Fig. 12): quadrant I ( $u^{\prime}>0$ and v' $>0)$; quadrant II ( $\mathrm{u}^{\prime}<0$ and $\left.\mathrm{v}^{\prime}>0\right)$; quadrant III $\left(\mathrm{u}^{\prime}<0\right.$ and $\left.\mathrm{v}^{\prime}<0\right)$ and quadrant IV $\left(\mathrm{u}^{\prime}>0\right.$ and $\left.\mathrm{v}^{\prime}<0\right)$.

Each quadrant represents an event; quadrant II is associated with "ejection" that can be schematically characterized by an upward movement $\left(v^{\prime}>0\right)$ of a low-speed fluid $\left(\mathrm{u}^{\prime}<0\right)$, in quadrant IV are the sweeps that are downward movements $\left(\mathrm{v}^{\prime}<0\right)$ of high speed $\left(\mathrm{u}^{\prime}>0\right)$ fluid. Events in these regions correspond to the production of turbulent energy (see Eq.(10)). Quadrants I and III are outward and inward interactions respectively.

In Fig. 12 the cross-hatched zone is bounded by the curves:

$\left|u^{\prime} \cdot v^{\prime}\right|=H \cdot \sigma_{u} \cdot \sigma_{v}$

where $\sigma_{u}$ and $\sigma_{v}$ are the root mean square values of the $u$ and $v$ velocity components. Only the region out of the cross-hatched zone is considered contributing to the events. The threshold values defined by $\mathrm{H}$, allow distinguishing high-magnitude events (H high) and most frequent events ( $\mathrm{H}$ equal to zero).

The quadrant contributions in each velocity field can be evaluated by the following discriminating function [25]:

$I_{H}^{i}(x, y, n)=\left\{\begin{array}{cc}1, & {\left[u^{\prime}(x, y, n), v^{\prime}(x, y, n)\right] \in Q^{i} \wedge\left|u^{\prime} \cdot v^{\prime}\right|>H \cdot \sigma_{u} \cdot \sigma_{v}} \\ 0, & \text { otherwise }\end{array}\right.$ 


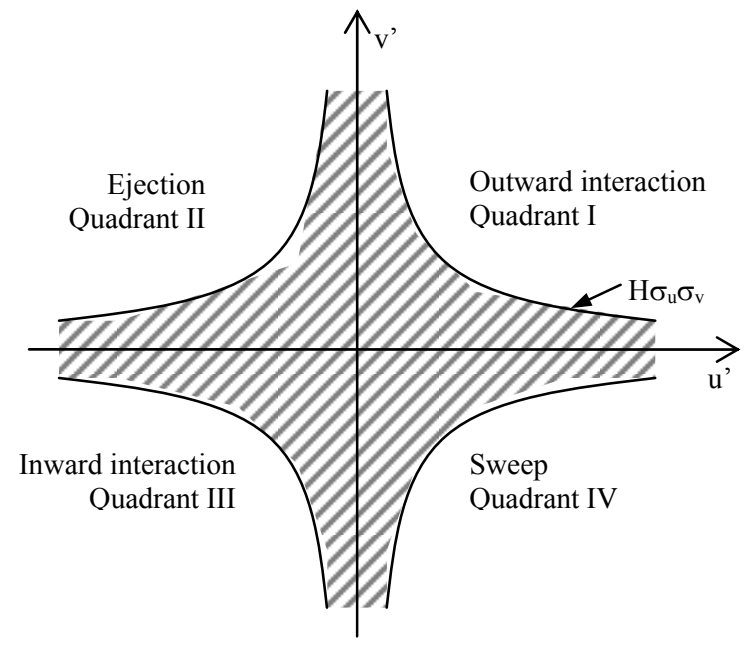

Fig. 12 - Definition sketch of the u'v' plane (after [23]).

The occurrence probability $\left(\mathrm{f}_{\mathrm{H}=\mathrm{x}}^{\mathrm{i}}\right)$ of each quadrant $\left(\mathrm{Q}^{\mathrm{i}}\right)$, over the $500(\mathrm{~N})$ instantaneous velocity fields can be determined by:

$f_{H=x}^{i}=\frac{\sum_{n=1}^{N} I_{H=x}^{i}(x, y, n)}{N}$

In this study two threshold values were adopted: $\mathrm{H}=0$, where all events within a quadrant are considered; and $\mathrm{H}=2$ where only the strongest events are considered, the value 2 has been used in other quadrant analysis studies $[26]$.

In Figs. 13 and 14 shows that the events associated to quadrant II and IV are the most frequent or have the highest probability in the flow field. For $\mathrm{H}=0$ (Fig 13) ejections $\left(\mathrm{Q}^{2}\right)$ have the highest probability of occurrence over the region near the pseudo-bottom and inside the step cavity, while the sweeps $\left(\mathrm{Q}^{4}\right)$ are the most frequent in the upper region of the overlying flow.

For the high-magnitude events, $\mathrm{H}=2$, occurs precisely the inverse. In the zone near the pseudo-bottom and inside the cavity, the highest probabilities of occurrence are for the sweeps and in the upper region of the coherent stream that skims over the steps the dominant event is the ejection (Fig 14).

The previous considerations seem to corroborate the flow visualizations over transverse square cavities made by Djenidi et al. (1999). The visualizations indicated random occurrence of three types of events: outflows from the cavities into the overlying flow; inflows into the cavities; and, periods where the overlying flow skims over the cavities with no significant exchange of fluid. The highest occurrence probability of high magnitude ejections in the overlying flow (Fig. 14) corroborates the existence of important outflows from the cavities. 


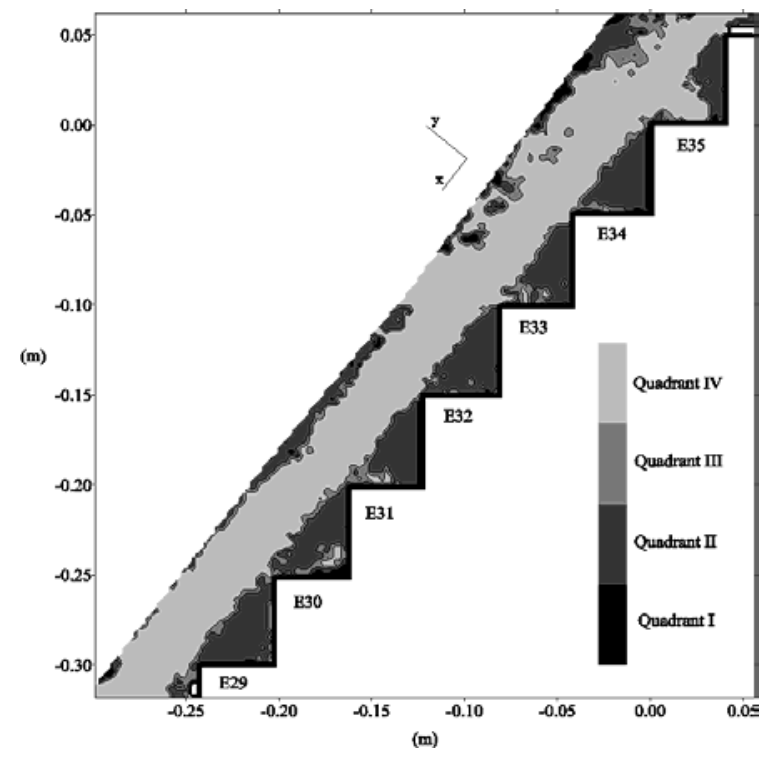

Fig. 13 - Contour map of the dominant quadrant in terms of occurrence probability for $\mathrm{H}=0$.

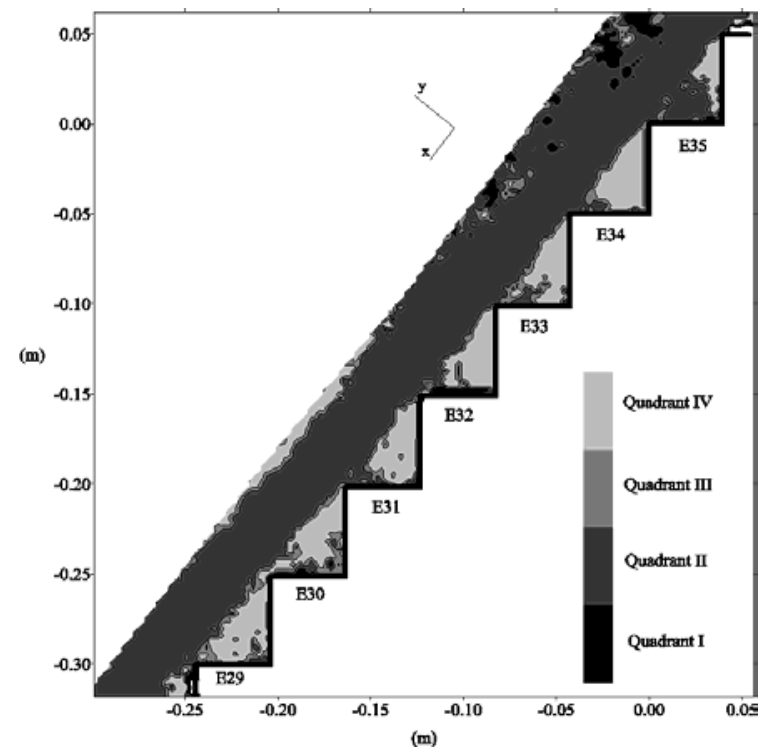

Fig. 14 - Contour map of the dominant quadrant in terms of occurrence probability for $\mathrm{H}=2$.

Continuity demands that an outflow which occurs at a spanwise location must be balanced, at the same time, by one or more inflows at other spanwise positions into the cavity, and that would explain why sweeps are dominant inside the cavity.

In [18] it is also observed that outflows occur sequentially in the downstream direction: an outflow from one cavity is followed by another in the adjacent downstream cavity. These sequences of outflows indicate that the initiating mechanism for the outflows may be triggered by the overlying flow rather than have its origin within 
the cavity $[27,18]$. The passage of quasi-streamwise vortices near the pseudo-bottom could pump fluid out of the cavities as these turbulent structures have associated pressure minimum at its core.

The outflows of strong magnitudes from the cavities into the overlying flow could play an important role in the increased turbulent intensities measured over stepped spillways in comparison with smooth spillways.

\section{CONCLUSIONS}

The experimental study presented herein investigated the developing flow region in stepped spillways with typical slopes of RCC dams. The main conclusions are summarized below:

1. In the region upstream the inception point the flow is accelerating and the turbulent boundary layer is developing and growing in the downstream direction. The recirculation inside the step cavity can be approximated to a solid body rotation. The velocities measured confirm the hypothesis of irrotational flow in the region closer to the free surface.

2. The boundary layer thickness, $\delta$, depends on the distance from the spillway crest and roughness height and can be predicted for stepped spillways by Eq. (3).

3. The Von Karman integral momentum equation was applied to estimate the flow resistance coefficient $\left(c_{f}\right)$. The mean value obtained was 0.031

4. The shear strain (Fig. 7) and vorticity (Fig. 8) contour maps agree in showing maximum levels just behind the step edges, where the separation of the shear layer begins. These regions can be associated with the formation and growth of large scale turbulent structures which are convected in the downstream direction. The swirling strength proved to be an appropriate quantity to identify existent eddies in the mean velocity field (Fig. 9).

5. The measured turbulence intensities $\left(\mathrm{T}_{\mathrm{u}}\right)$ between 0.40 and 0.65 near the pseudo-bottom are much higher than the maximum levels reported for smooth open channels.

6. A quadrant analysis was performed to study turbulent structures. It shows that "ejections" are the most frequent events in the region near the pseudo-bottom and "sweeps" dominate the upper region of the skimming flow, Fig. 13. When considering only high magnitude events $(\mathrm{H}=2)$, the opposite situation occurs. The "sweeps" are dominant near the pseudo-bottom and inside the cavity and the "ejections" are more frequent in the upper region of the overlying flow, Fig. 14. This analysis seems to corroborate the flow visualizations of [18]. Along the span of the cavities, the outflows alternate with inflows of appreciable magnitude and contribute in producing and maintaining turbulence intensities and Reynolds 
shear stresses by exchanging momentum between the cavities and overlying layers. The fluid trapped within the cavities functions as a natural reservoir of low-momentum that facilitates the exchange of momentum between cavities and the overlying stream. It is conjectured that these would help maintaining a higher turbulent energy of the flow over a stepped spillway in comparison with a smooth spillway.

\section{ACKNOWLEDGEMNETS}

The authors would like to acknowledge CITEEC (Centro de Innovación Tecnoloxica en Edificación e Enxeneria Civil) and Prof. Jerónimo Puertas from A Coruña University for giving the conditions for the realization of the experimental work. The first author acknowledges the financial support of the Fundação para a Ciência e Tecnologia (Portugal, Praxis XXI, BD/3056/2000) and the helpful discussions of Dr. Gerber Van der Graaf.

\section{NOMENCLATURE}

$E=$ energy head;

$\mathrm{E}_{0}=$ maximum energy head;

$\mathrm{H}=$ hole size value;

$\mathrm{I}_{\mathrm{H}}^{\mathrm{i}}=$ discriminating function;

$\mathrm{L}_{\mathrm{cav}}=$ distance between step edges, roughness spacing;

$\mathrm{N}=$ exponent of velocity power law and number of PIV realizations;

$\mathrm{P}=$ rate of production of turbulent kinetic energy;

$Q^{i}=$ quadrant $i$ of the plane $u^{\prime} v^{\prime}$;

$\mathrm{T}_{\mathrm{u}}=$ turbulence intensity in the flow direction;

$\mathrm{U}(\mathrm{y})=$ mean velocity in $\mathrm{x}$ direction at coordinate $\mathrm{y}$;

$\mathrm{U}_{0}=$ ideal-fluid flow velocity;

$\overline{\mathrm{U}}=$ mean flow velocity;

$\mathrm{V}(\mathrm{y})=$ mean velocity in $\mathrm{y}$ direction at coordinate $\mathrm{y}$;

$\mathrm{X}=$ streamwise distance from spillway crest to the outer step edge;

$Z=$ factor related with confidence level;

$b(x)=$ characteristic width of the mixing layer;

$\mathrm{c}_{\mathrm{f}}=$ flow resistance coefficient; 
$\mathrm{d}=$ flow depth;

$\mathrm{d}_{0}=$ ideal-fluid depth;

$\mathrm{f}_{\mathrm{H}}^{\mathrm{i}}=$ occurrence probability event I with hole-size value of $\mathrm{H}$;

$\mathrm{g}=$ gravitational acceleration;

$\mathrm{h}=$ step height;

$k=$ turbulent kinetic energy;

$\mathrm{k}_{\mathrm{s}}=\mathrm{h} \cdot \cos \alpha$ roughness height perpendicular to pseudo-bottom;

$\mathrm{q}=$ discharge per unit width;

$\mathrm{u}=$ instantaneous velocity in $\mathrm{x}$ direction;

$\mathrm{u}^{\prime}=\mathrm{u}-\mathrm{U}$ velocity fluctuation in $\mathrm{x}$ direction;

$\mathrm{v}=$ instantaneous velocity in $\mathrm{y}$ direction;

$\mathrm{v}^{\prime}=\mathrm{v}-\mathrm{V}$ velocity fluctuation in $\mathrm{y}$ direction;

$\mathrm{x}=$ streamwise coordinate axis;

$y=$ transverse coordinate axis;

$\mathrm{y}_{\alpha}=$ coordinate $\mathrm{y}$ where $\mathrm{U}=\alpha \mathrm{U}_{0}$;

$\mathrm{z}=$ spanwise coordinate axis;

$\Delta \mathrm{E}=$ head of energy loss;

$\Delta \mathrm{X}=$ vector spacing;

$\alpha=$ chute angle from horizontal;

$\delta=$ boundary layer thickness;

$\delta^{*}=$ displacement thickness;

$\delta^{\mathrm{e}}=$ energy thickness;

$\varepsilon_{\text {mean }}=$ uncertainty in the mean value;

$\varepsilon_{\mathrm{RMS}}=$ uncertainty in the RMS value;

$\varepsilon_{\mathrm{xy}}=$ mean shear strain;

$v=$ kinematic viscosity of water;

$v_{\mathrm{t}}=$ turbulent kinematic viscosity;

$\lambda=$ eigenvalue of the velocity gradient tensor;

$\theta=$ momentum thickness; 
$\rho=$ density of water;

$\sigma_{\mathrm{u}}=$ root mean square of streamwise component of velocity;

$\sigma_{\mathrm{v}}=$ root mean square of transverse component of velocity;

$\tau_{\mathrm{w}}=$ pseudo-bottom shear stress; and

$\omega_{\mathrm{z}}=$ mean spanwise vorticity 


\section{REFERENCES}

[1] Essery, I., and Horner, M., 1978, The hydraulic design of stepped spillways, CIRIA Report $\mathrm{n}^{\mathrm{o}} 33$, London, $2^{\text {nd }}$ edition.

[2] Chanson, H., 1995, Hydraulic Design of Stepped Cascades, Channels, Weirs and Spillways, Pergamon, Oxford.

[3] Chanson, H., 2001, The hydraulics of stepped chutes and spillways, Swets \& Zeitlinger, Lisse, the Netherlands.

[4] Gonzalez, C., and Chanson, H., 2004, "Interactions Between Cavity flow and Main Stream Skimming Flow: an Experimental study", Canadian Journal of Civil Engineering, 31, pp. 33-44.

[5] Boes, R.M., and Hager, W., 2003, “Two-Phase Flow Characteristics of Stepped Spillways”, J.Hydraul. Eng., 129 (9), pp. 661-670.

[6] Matos, J., 1999, “Air Entrainment and Energy Dissipation on Flow Over Stepped Spillways”. Ph. D. thesis, Technical Univ. of Lisbon, IST, Lisboa, (in Portuguese).

[7] Ohtsu, I., Yasuda, Y., and Takahashi, M., 2004, "Flow Characteristic of Skimming flow in Stepped Channels” J.Hydraul. Eng., 130 (9), pp. 860-869.

[8] Ohtsu, I, and Yasuda, Y., 1997, “Characteristics of Flow Conditions on Stepped Channels". Proc. 27 $7^{\text {th }}$ IAHR Biennal Congress, San Francisco, Theme D, pp. 583-588

[9] Chanson, H., and Toombes, L., 2002, “Air Water Flows Down Stepped Chutes: Turbulence and Flow Structure Observations”, International Journal of Multiphase Flow, 28, pp. 1737-1761.

[10] Amador, A., Sánchez-Tembleque, F., Sánchez-Juny, M., Puertas, J., and Dolz, J., 2004, "Velocity and Pressure Field in Skimming Flow in Stepped Spillways", Hydraulics of Dams and River Structures, F. Yanzdandoost and J.Attari, eds., Taylor \& Francis, London, pp. 279-286.

[11] Westerweel, J., Dabiri, D., and Gharib, M., 1997, “The Effect of a Discrete Window Offset on the Accuracy of the Cross-Correlation Analysis of Digital PIV Recordings”, Experiments in Fluids, 23, pp. 20-28.

[12] Keane, R., and Adrian R., 1990, “Optimization of Particle Image Velocimeters Part I: Double Pulsed Systems”, Meas. Science Technology, 1, pp. 1202-1215.

[13] Westerweel, J., 1994, "Efficient detection of spurious vectors in particle image velocimetry", Experiments in Fluids, 16, pp. 236-247.

[14] Freek C., Sousa J., Hentschel W., and Merzkirch W., 1999, “On the Accuracy of a MJPEG-Based Digital Compression PIV-System", Experiments in Fluids, 27, pp. 310-320. 
[15] Rajaratnam, N., 1990, “Skimming Flow in Stepped Spillways”, J. Hydraul. Eng., 116, pp. 587-591.

[16] U.S. Bureau of Reclamation, 1977, Hydraulic Design Criteria-Sheet 111-18 to 111-18/5, Corps of Engineers, USA

[17] Pope, S., 2000, TurbulentFlows, Cambridge University Press, Cambridge,UK.

[18] Djenidi, L., Elavarasan, R., and Antonia, R., 1999, “The Turbulent Boundary Layer Over Transverse Square Cavities” J. Fluid Mechanics, 395, pp. 271-294.

[19] Cain, P., 1978, "Measurements Within Self-Aerated Flow on a Large Spillway", Ph.D. thesis, Univ. of Canterbury, New Zealand.

[20] Chanson, H., 1989, "Flow Downstream of an Aerator. Aerator Spacing”, J. Hydraul. Research, 27 (4), pp.519-536.

[21] Adrian, R., Christensen, K., and Liu, Z., 2000, “Analysis and Interpretation of Instantaneous Turbulent Velocity Fields", Experiments in Fluids, 29, pp.275-290.

[22] Sousa, J., and Pereira, J., 2002,. "DPIV Study of the Effect of a Gabble Roof on the Flow Structure Around a Surface-Mounted Cubic Obstacle”, Experiments in Fluids, 37, pp. 409-418.

[23] Nezu, I., and Nakagawa, 1993, Turbulence in open-channel flows, IAHR monograph series, Ed. Balkema, The Netherlands.

[24] Willmarth, W., and Lu, S., 1972, "Structure of the Reynolds Stress Near the Wall”, J. Fluid Mechanics, 55, pp. 65-92.

[25] Cellino, M., and Lemmin, U., 2004, "Influence of Coherent Flow Structures on the Dynamics of Suspended Sediment Transport in Open-Channel Flow”, J.Hydraul. Eng., 130 (11), pp.1077-1088.

[26] Belanger, T., and Roy, A., 1998, "Effects of a Pebble Cluster on the Turbulent Structure of a Depth-Limited Flow in a Gravel-Bed River", Geomorphology, 25, pp. 249-267.

[27] Townes, H., and Sabersky, R., 1966, “Experiments on the Flow Over a Rough Surface”, Int. J. Heat Mass Transfer, 9, pp. 729-738. 


\section{$\underline{\text { List of Figures }}$}

Fig. 1 - a) Developing flow region in stepped spillway with $\mathrm{q}=0.11 \mathrm{~m}^{2} / \mathrm{s}, \mathrm{h}=0.05 \mathrm{~m}, \alpha=51.3^{\circ}$. b) Image captured by CCD camera for steps E34 (X/ks=13.04) and E33 at $(\mathrm{X} / \mathrm{ks}=15.09)$.

Fig. 2 - Contour map of mean absolute velocity $(|\mathrm{U}|)$.

Fig. 3 - Evolution of the $\delta(\diamond), \delta^{*}(\square), \theta(\circ)$.

Fig. 4 - Flow resistance coefficient $\left(\mathrm{c}_{\mathrm{f}}\right)$ along the stepped spillway.

Fig. 5 - Mean velocity profiles $\left(\mathrm{U} / \mathrm{U}_{0}\right)$ normal to the pseudo-bottom, along the step cavities $\left(\mathrm{L}_{\mathrm{cav}}\right)$ analyzed.

Fig. 6 - Mean velocity profiles $\left(\mathrm{U} / \mathrm{U}_{0}\right)$ and variation of $\mathrm{y}_{\alpha}$ along the step cavities analyzed. Symbols as in Fig. 5.

Fig. 7 - Contour map of mean shear strain $\left(\varepsilon_{\mathrm{xy}}\right)$.

Fig. 8 - Contour map of mean spanwise vorticity $\left(\omega_{\mathrm{z}}\right)$.

Fig. 9 - Contour map of swirling strength.

Fig. 10 - Contour map of turbulent kinetic energy (k).

Fig. 11- Turbulence intensity $\left(\mathrm{T}_{\mathrm{u}}\right)$ profiles normal to the pseudo-bottom, along the step cavities analysed. Symbols as in Fig. 5.

Fig. 12 - Definition sketch of the u'v' plane (after [23]).

Fig. 13 - Contour map of the dominant quadrant in terms of occurrence probability for $\mathrm{H}=0$.

Fig. 14 - Contour map of the dominant quadrant in terms of occurrence probability for $\mathrm{H}=2$. 